\title{
Synthesis and Applications of Polymeric Reagent p-Substituted Triphenylamine
}

\author{
Ideisan I. Abu-Abdoun*
}

Department of Chemistry, University of Sharjah, Sharjah P.O. Box 27272, UAE

\begin{abstract}
Chemical modification of chloromethylstyrene - styrene copolymer throughout reaction of p-substituted carboxylic acid group of bis-(4,4 -dibromo)-4"-triphenylamine carboxylic acid with the chloromethyl group attached to a phenyl group was carried out on soluble copolymer and polymeric cross-linked copolymer. Chemical oxidation of the neutral p-substituted triphenylamine with antimony pentachloride in dichloromethane solvent gives the corresponding cation - radical salt with the counter ion antimony hexachloride $\left(\mathrm{SbCl}_{6}{ }^{-}\right)$. The isolated deep blue color cation radical salt is soluble or in insoluble (resin) form in the copolymer was used as a thermal cationic initiator for the polymerization of epoxy and vinyl monomers at room temperature. The cation radical resin showed good activity and stability compared to the soluble polymeric cation radical, both can initiate the cationic polymerization of cyclohexene oxide and $\mathrm{N}$ vinylcarbazole in dichloromethane at room temperature.
\end{abstract}

Keywords: Polymeric cation radical, substituted triphenylamine, cationic polymerization reaction, polymeric triphenylamine, chloromethyl styrene resin.

\section{INTRODUCTION}

Chloromethylated polystyrenes are key intermediates in the preparation of amino-exchange resins, supports solid-phase peptide synthesis, and supports for polymeric reagents and catalysts [1]. The polymer support might be a linear soluble species, or porous cross-linked polystyrene prepared by copolymerization of styrene with divinylbenzene, having a different density of crosslinks. The chemically bound functional group might be a reagent, a protecting group, a ligand, a metal complex catalyst or some other catalytic species e.g., an acid or base, or a phase transfer catalyst [2].

Polymeric reagents are easily separable from low molecular weight compounds; with cross-linked insoluble polymers simple filtration is usually sufficient; selective precipitation removes soluble polymers. This enables the polymeric reagent to be used in either columns or batch processes, and it may be regenerated several times. Polymeric reagents also often lack many inconvenient properties of the corresponding low-molecular-weight reagents, such as liability, volatility, toxicity or color. The excess starting material is easily separated from the product and may often be reused, and reaction side products are often easily removed [3].

*Address correspondence to this author at the Department of Chemistry, University of Sharjah, Sharjah P.O. Box 27272, UAE;

E-mail: abuabdoun@sharjah.ac.ae
Polymers having triphenylamine units have been extensively used as excellent hole transport materials and photoconductors based on their ability to form stable cation radical and high drift mobility $[4,5]$ and in advanced materials for various optoelectronic applications, such as electrochromic, electro-fluoro chromic, and polymeric memory devices [6].

In our early works with cation radical salts of $p$ substituted triphenylamine, phenothiazine and tetraphenylenediamine have been used to accomplish extremely efficient one electron transfer, to induce cationic polymerization reactions of cyclohexene oxide, THF and $\mathrm{N}$ - vinylcarbazole monomers [7-9]. and also in electrochemical modification of electrodes [10].

Thus, our interest in the polymeric cation radical of para-substituted triphenylamine leads us to the synthesis of triphenylamine containing polymeric reagent, through coupling reactions of the copolymer of chloromethyl styrene - styrene with 4-carboxyl-4', 4"dibromotriphneylamine. The obtained copolymer in this system carrying p-substituted triphenylamine can be oxidized chemically to give the polymeric cation radical salt, which is found to be useful for the cationic polymerization reactions of epoxides and vinyl monomers and other isomerization reactions.

\section{EXPERIMENTAL}

\subsection{Chemicals and Solvents}

Substituted triphenylamine (4 and 5) were obtained as reported early [11]. Monomers and solvents were 
purified according to standard procedures. Other chemicals were of reagent grade and were used without further purification.

\subsection{Spectroscopic Measurements}

Ultraviolet spectra were obtained on a Unicam SP1800 Ultraviolet spectrophotometer. Infrared spectra were recorded using potassium bromide ( $\mathrm{KBr}$ disc) with a Perkin - Elmer grating infrared spectrophotometer (Model 577).

\subsection{Polymerization}

The selected amounts of monomer and initiator in dichloromethane were placed in a reaction tube and placed in a holder and left for the required period immersed in the water bath at $25{ }^{\circ} \mathrm{C}$. The polymer was precipitated in methanol, in case of polymerization by the resin cation radical; to the selected amount of resin dichloromethane was added to allow swallow the resin. Directly after, the monomer was added and left for a selected time, the filtered polymer solution was precipitated in methanol, later filter and dry the obtained polymer, this process was repeated several times and between each process swelling of the resin in dichloromethane was repeated too. The yield was filtered, dried and weighed. The polymer yield and the rate of polymerization were determined gravimetrically [12]. While in the case of soluble polymeric cation radical the polymerization was carried out as in the case of homogeneous polymerization system where after polymerization time the polymerized solution powered in 5-folds excess methanol, filtered and dried to recover the obtained polymer.

\subsection{Synthesis of p-Substituted Triphenylamine}

Bis-(4,4'-dibromo)-4"-carboxylcarbonyltriphenylamine (4) was prepared according to the method established by Abu-Abdoun and Ledwith [13], as shown in Scheme 1.

\section{RESULTS AND DISCUSSIONS}

\subsection{Synthesis of the Functional Soluble Copolymer p-Chloromethyl Styrene-Styrene Bounded to 4- Carboxyl 4'4"-Dibromo Triphenylamine (5)}

A soluble copolymer of chloromethyl styrene styrene was prepared according to the method described by Shuji Kondo et al. [13].

The esterification reaction of poly[(p-chloromethyl) styrene] (PCMS) with carboxylic group of triphenylamine compound (4) proceeded smoothly to give the corresponding polymer with pendant ester group (5) using 1,8-diazabicyclo-5.4.0]-7-undecene (DBU) as an organic base even at $60^{\circ} \mathrm{C}$ in $\mathrm{N}, \mathrm{N}$ dimethylformamide (DMF) solvent [14].

Typical Procedure for the Reaction of Pendant Chloromethyl Group in the polymer with carboxylic Acid

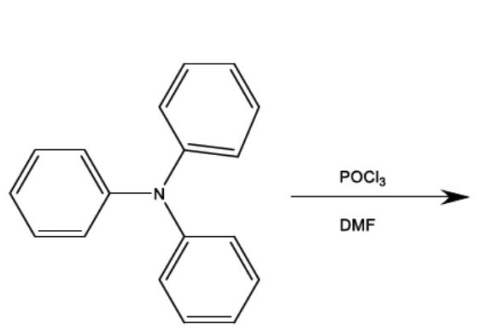

(1)

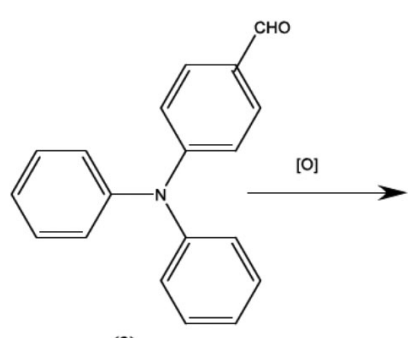

(2)

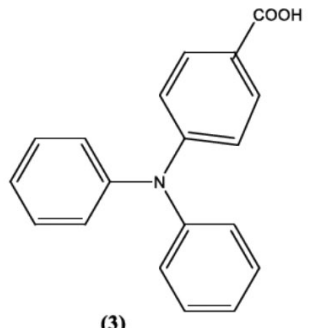

(3)

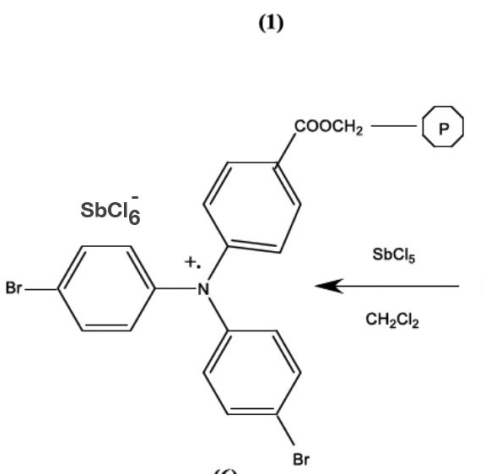

(6)
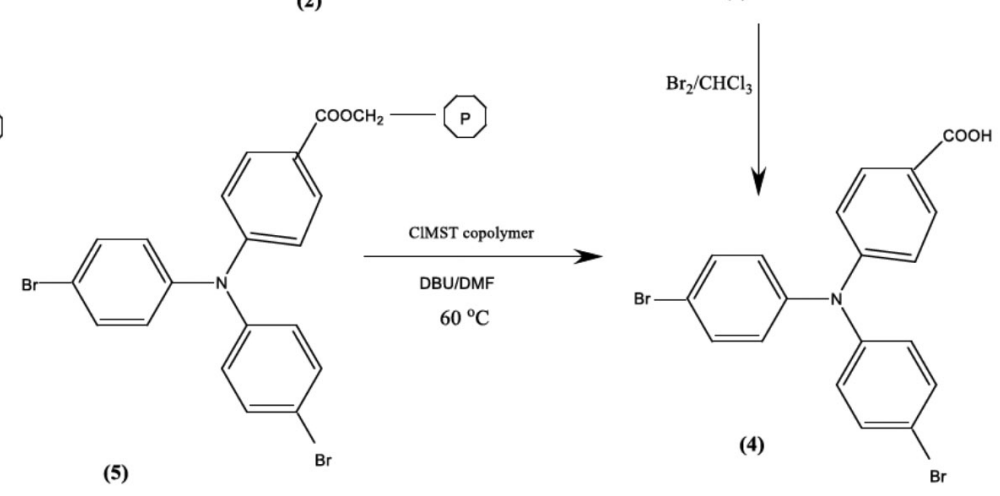

Polymeric soluble cation radical

Scheme 1: Synthesis of the soluble polymeric reagent from chloromethylstyrene copolymer and p-substituted triphenylamine. 
PCMS (7) (2.0 gm) was dissolved in $30 \mathrm{ml}$ of DMF, and then carboxylic acid triphenylamine $(4)(1.35 \mathrm{gm})$ and DBU $(1.5 \mathrm{gm})$ were added into the solution. The mixture was stirred at $60{ }^{\circ} \mathrm{C}$ for 4 hours, cool to room temperature and then poured into methanol to precipitate the polymer, which was reprecipitated twice from dichloromethane into methanol, filtered, and dried under vacuum at room temperature to give slightly yellow plates. Yield $=2.8 \mathrm{gm} . v_{\max }(\mathrm{KBr}$ disc $), 1720$ $(\mathrm{C}=\mathrm{O}), 1605$ (N-Ar), 1580, 1500, 1480, 1435, 1375, 1312, 1270 (broad the most intense band), 1190, 1175, $1110,1070,1007,85,820,765,710,695 \mathrm{~cm}^{-1}$.

\subsection{Oxidation of the Polymeric Triphenylamine Coupling Product (6)}

A sample of the polymer (5) obtained above was treated under nitrogen in dichloromethane with $\mathrm{SbCl}_{5}$ in the same solvent dropwise, after cooling the reaction was instantaneous and the blue colored mixture was left stirring for about 5 minutes, then treated with a 4fold excess of cold benzene which precipitated the deep blue salt. It was then quickly filtered and washed with cold benzene twice, then dried, and stored in a stoppered flask in a cold place.

The salt (6) was stable and soluble in dichloromethane and acetonitrile, but it decomposed to a colourless solution in alcohol, petroleum ether, and acetone.

The isolated salt was found to be partially soluble after few days when stored at room temperature either as a solid or in solution without losing its blue color. Figure 1 shows the UV spectra of the soluble neutral

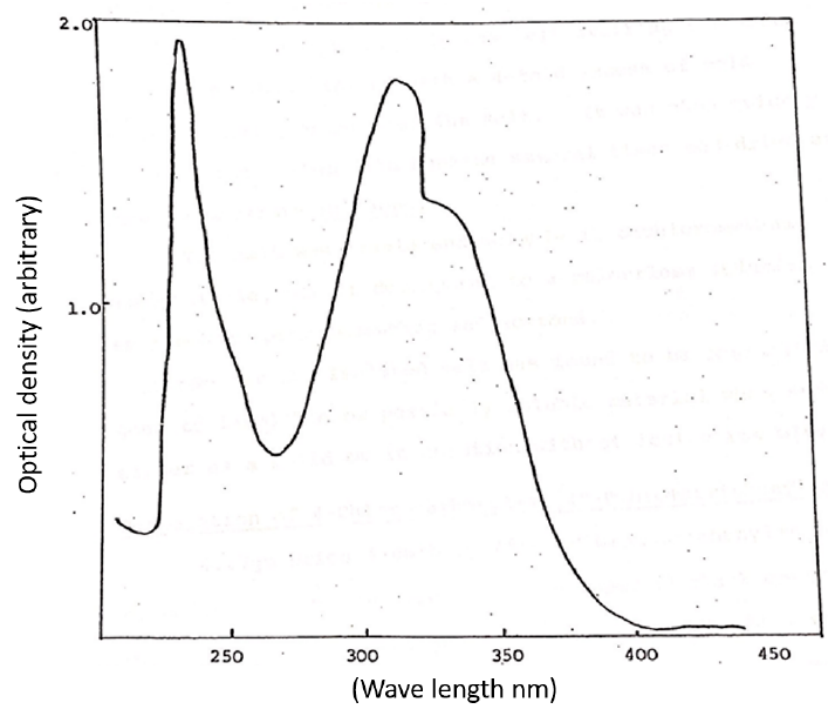

Figure 1: Absorption Spectra of (5) in dichloromethane. amine (5) in dichloromethane, and Figure 2 shows the absorption spectra of the polymeric soluble cation radical (6). The polymerization solution of cyclohexene oxide in dichloromethane before precipitation is shown in Figure 3.

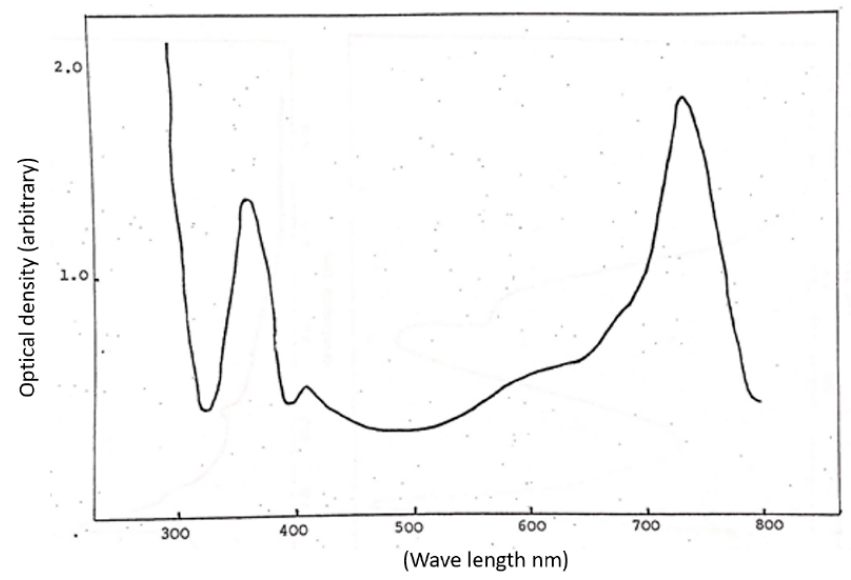

Figure 2: Absorption Spectra of (6) in dichloromethane.

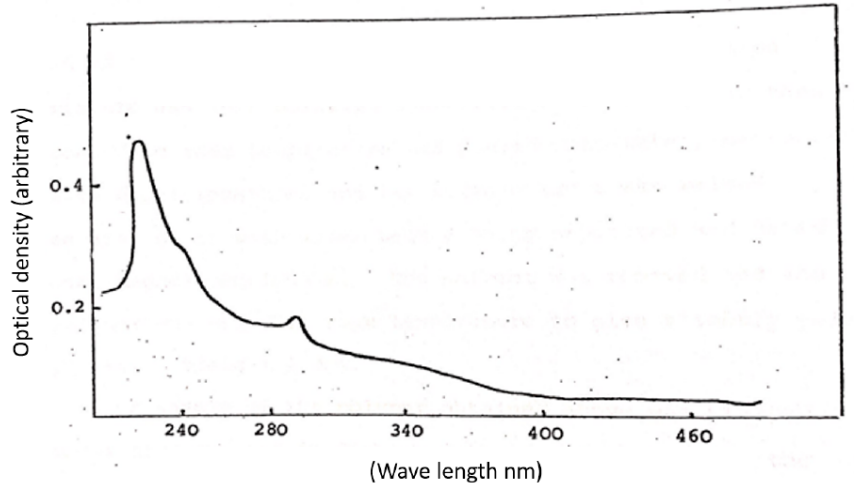

Figure 3: Absorption of polymerization reaction mixture of cyclohexene oxide by (6).

\subsection{Preparation of $\mathrm{p}$-Chloromethylstyrene - Styrene Resin (7)}

P-Chloromethylstyrene resin containing 16.7\% chloromethylstyrene groups and $83.3 \%$ styrene groups was prepared according to the method established by Arshady et al. [15].

The reaction vessel was fitted with a reflux condenser, a nitrogen inlet and a mechanical stirrer, and loaded with $350 \mathrm{ml}$ deionized water and $1.5 \mathrm{gm}$ poly(vinylpyrrolidene) (PVP), $1.0 \mathrm{gm}$ calcium sulfate, $0.4 \mathrm{gm}$ calcium orthophosphate, and $30 \mathrm{gm}$ sodium chloride. The vessel was placed in a water bath at $80^{\circ}$ $\mathrm{C}$ and the mixture was flushed with oxygen-free nitrogen for approximately 30 minutes before a slow stream of nitrogen was allowed to pass over the reaction mixture and the stirrer was adjusted to an 
appropriate speed of 300 r. p.m. The monomer mixture contained $10 \mathrm{gm}$ styrene, $0.25 \mathrm{gm}$ divinylbenzene, 2.0 gm p-chloromethyl styrene and $0.3 \mathrm{gm}$ azobisizobutyronitrile (AIBN) free radical initiator. This was added through the sampling arm. After 5-6 hours the vessel was removed from the constant temperature bath.

Polymer beads were purified and recovered according to the following washing-decantation sequence:

a. The reaction mixture was stirred in three litres of water for 10 minutes, allowed to stand and the less dense dust-like fine suspension was decanted out from the polymer beads. This process was repeated a few times until no finer particles separated.

b. The polymer particles were stirred and decanted successively with three litres of water-methanol mixtures $(5: 1,2: 1,1: 1)$.

c. The polymer beads were stirred and decanted successively with three litres of water-methanolacetone $(7: 2: 1)$, one litre of methanol-acetone $(1: 1)$ and finally pure methanol and then dried in a vacuum oven at $50{ }^{\circ} \mathrm{C}$. Yield $=7.0 \mathrm{gm}$.

Elemental analysis was carried out assuming the degree of polymerization is 100, and the chloromethylstyrene group percentage is 17. Expected: Carbon $=87.3$, found 87.39. Hydrogen Expected =7.2, found 7.41. Chlorine: Expected 5.37, found 5.10.

\subsection{Reaction of the Resin (7) with (4) to Prepare (8)}

A $0.2 \mathrm{gm}$ Chloromethylstyrene resin (7) and $0.5 \mathrm{gm}$ of the 4-carboxyl-4'-dibromotriphenylamine mixture was heated at $60{ }^{\circ} \mathrm{C}$ in $20 \mathrm{ml} D M F$ in presence of 0.2 gram DBU as reported in preparation of (5) for 4 hours. After cooling out the reaction to room temperature, the reaction mixture was filtered through a glass sinter, provided with suction tail and tap through a Buchner flask, and washed with excess dichloromethane twice, followed by aqueous methanol, and then washed with acetone ( 3 - 4 times). The resin was allowed to stand for at least two minutes with each washing step to ensure that no unreacted amine was left inside the polymer particles. The polymeric resin was dried at 50 ${ }^{\circ} \mathrm{C}$. Elemental \% analysis was carried out and presented below: Expected: Carbon $=75.15$, found 81.12, Hydrogen Expected $=5.6$, found 6.73. Nitrogen: Expected 1.30, found 1.08

\subsection{Oxidation of the Polymeric Triphenylamine Resin, Preparation of (9)}

A sample of the copolymer obtained above was treated under nitrogen in dichloromethane, with $\mathrm{SbCl}_{5}$ in the same solvent. The reaction was instantaneous, and the blue colored mixture was left stirring for about 10 minutes, washed several times with cold benzene, then filtered and dried at room temperature invacuo. The deep blue salt was stored in a cold place, without losing its color for more than one year.

The salt (9) was stable and insoluble in dichloromethane and acetonitrile, but decomposed to a

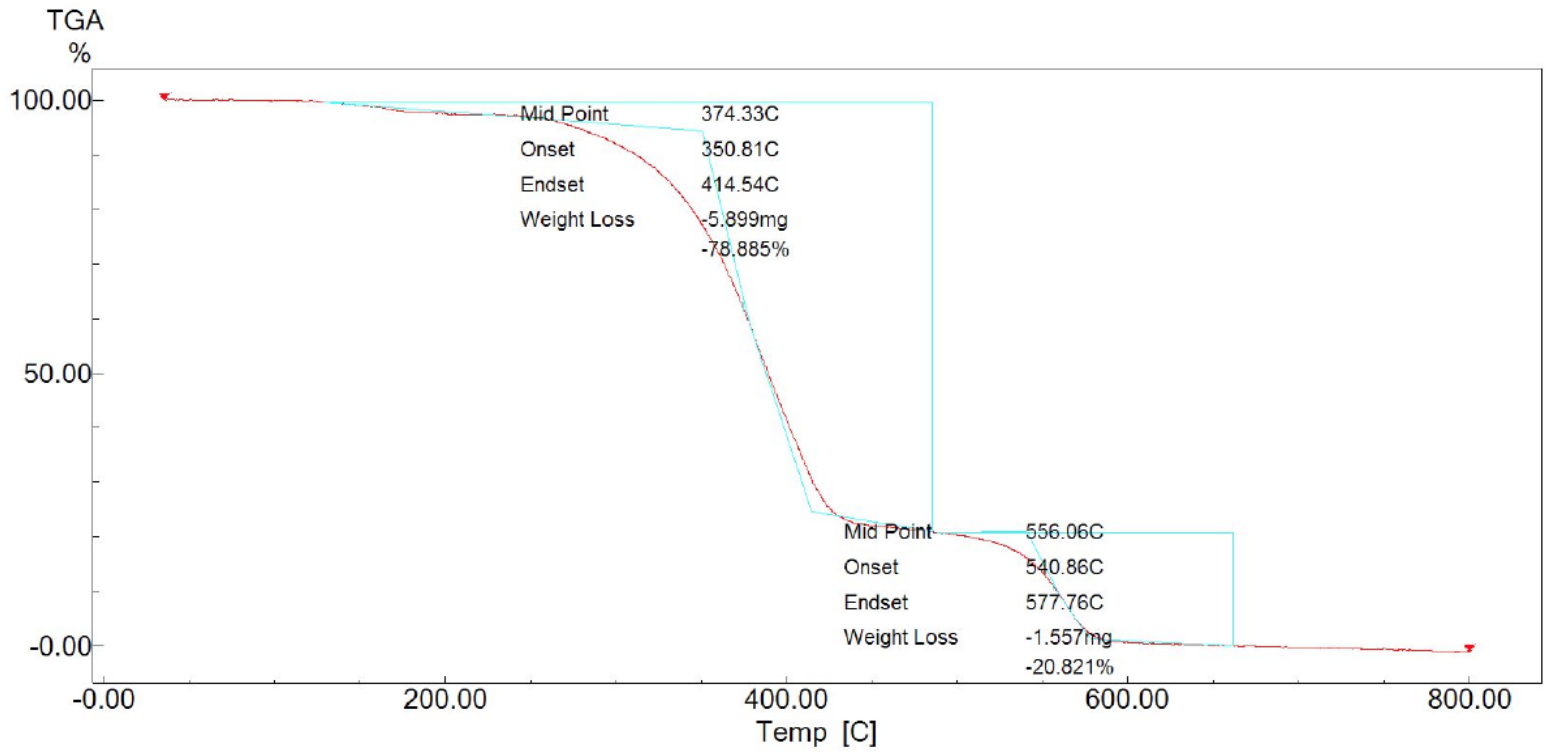

Figure 4: TGA plot for the styrene-Chloromethylstyrene copolymer resin $17 \% \mathrm{Cl}$. 


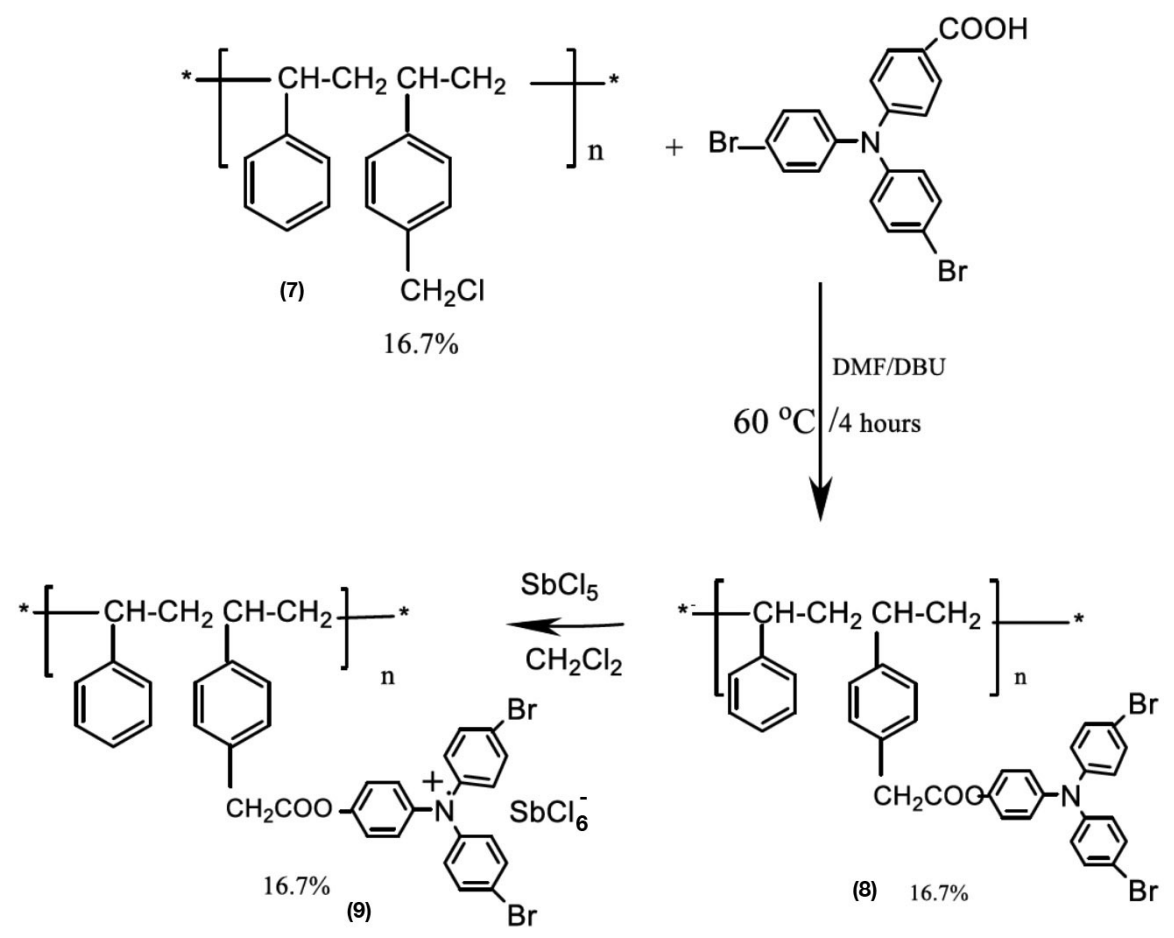

Scheme 2: Coupling of Chloromethylstyrene polymeric resin p-substituted triphenylamine.

colorless solution in alcohol, petroleum ether and acetone inless rate than (6).

TGA analysis of the copolymer $17 \% \mathrm{Cl}$ (7) under oxygen atmosphere showed significant weight loss in the temperature range of $374-414{ }^{\circ} \mathrm{C}$ as illustrated in Figure 4. This weight loss is mainly due to the halogen atom $(\mathrm{Cl})$ splitting which leads to cross-linked dimeric form which decomposes further at $556-577^{\circ} \mathrm{C}$.

\subsection{Attempts in Polymerization of Selected Monomers}

Polymerization was carried out as explained early in the experimental section 2.3. For the purpose of comparison in reactivity and stability of polymeric resin and soluble polymeric reagent prepared cation radical salts, the type and concentration of each monomer was fixed, and only varies the time of polymerization. The concentration of the polymeric initiator salt was in the range $5.0 \times 10^{-3} \mathrm{M}$, and 2.0 grams of the monomer was used.

a. Polymerization of cyclohexene oxide $(\mathrm{CHO})$ at room temperature (Table 1):

It is clear from Table 1, the polymeric crosslinked resin (9) is more active as a polymeric reagent for the polymerization of cyclohexene oxide than (6) in dichloromethane at room temperature

Table 1: Polymerization of Cyclohexene Oxide (CHO) by Polymer (6) and Resin (9)

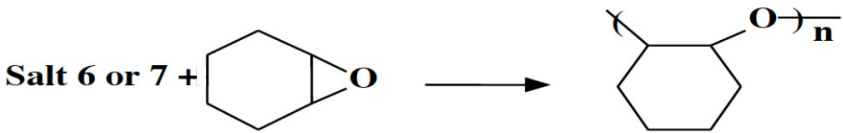

\begin{tabular}{|c|c|c|c|}
\hline & Soluble cation radical (6) & Insoluble Resin (9) & Remarks \\
\hline \hline Time Minutes & \% conversion & \% conversion & Blue reaction mixture \\
\hline 5 & 6 & 20 & Blue reaction mixture \\
\hline 10 & 8 & 36 & Blue reaction mixture \\
\hline 15 & 35 & 58 & Blue reaction mixture \\
\hline
\end{tabular}


Table 2: Polymerization of N-Vinylcarbazole (NVC) by Polymer (6) and Resin (7)

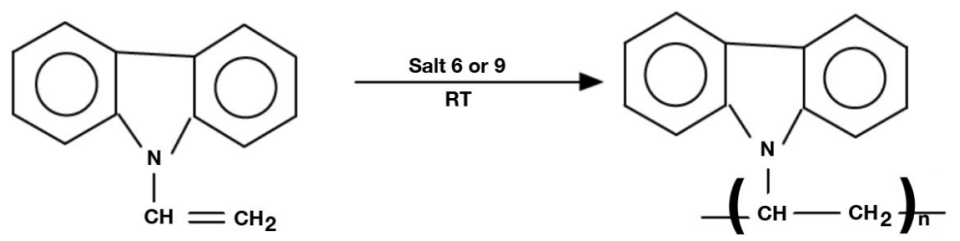

\begin{tabular}{|c|c|c|c|}
\hline Time & Soluble cation radical (6) & Insoluble Resin (9) & Remarks \\
\hline \hline minutes & \% conversion & \% Conversion & Blue reaction mixture \\
\hline 2 & 34 & 23 & Blue reaction mixture \\
\hline 10 & 57 & 48 & Blue reaction mixture \\
\hline 15 & 92 & 76 & Blue reaction mixture \\
\hline
\end{tabular}

b. Polymerization of N-vinylcarbazole (NVC) at room temperature as shown in Table 2.

Also, Table 2 shows different reactivity, as the polymeric crosslinked resin (9) is less active as a polymeric reagent for the polymerization of NVC than (6) at room temperature and in dichloromethane. This variation in reactivity could be due to the effect of the counter ion stability on the propagated chain type for both monomers.

\section{CONCLUSIONS}

p-substituted triphenylamine coupled to the chlomethylated styrene copolymer in a soluble and crosslinked form prepared and found to be useful as the polymerization of cyclohexene oxide and $\mathrm{N}$ vinylcarbazole. The resin form of the obtained polymeric triphenylamine cation radical salt was found to be more stable than the soluble polymeric one. Heterogenization of homogeneous catalyst in this work is well demonstrated and can be applied to many organic or polymerization reactions in future work.

\section{REFERENCES}

[1] Camps M, Chatzopoulos M, Camps J-M, Jean-Pierre. Montheard Chloromethylation of Polystyrenes and Styrene Copolymers. Applications. Journal of Macromolecular Science Part C Polymer Reviews 2006; 27(3): 505-557. https://doi.org/10.1080/07366578708078821

[2] Hui $\mathrm{Ci}$, Chen $\mathrm{F}, \mathrm{Pu} \mathrm{F}, \mathrm{Xu}$ J. Innovation in protecting-groupfree natural product synthesis. Nature Reviews Chemistry 2019; 3: 85-107.

https://doi.org/10.1038/s41570-018-0071-1

[3] Abu-Abdoun II. Cationic Photopolymerization by Polymeric Triphenyl Phosphonium Salts. Chemical Science International Journal 2019: 27(4): 1-7. https://doi.org/10.9734/CSJI/2019/v27i430118

[4] Naito K, Miura A. Molecular Design for Nonpolymieric Organic Dye Glasses with Thermal Stability: Relations between Thermodynamic Parameters and Amorphous Properties. Phys Chem 1993; 97: 6240-6248. https://doi.org/10.1021/j100125a025

[5] Park S-H, Ogino K. Synthesis and characterization of photorefractive polymers with triphenylamine unit and NLO chromophore unit on a side chain. Polymers for Advanced Technologies 2000; 11(7): 349-358. https://doi.org/10.1002/1099-1581(200007)11:7<349::AIDPAT978>3.0.CO;2-Z

[6] Yen H-J, Liou G-S. Design and preparation of triphenylamine-based polymeric materials towards emergent optoelectronic applications. Progress in Polymer Science 2019; 89: 250-287.

https://doi.org/10.1016/j.progpolymsci.2018.12.001

[7] Abu-Abdoun II, Ledwith A. Polymerization Induced by N, N $\mathrm{N}^{\prime}, \mathrm{N}^{\prime}$ Tetraphenyl-p-phenylenediamine Cation Radical Salts. Journal of Macromolecular Science, Part A: Pure and Applied Chemistry 1998; 35(4): 673-690. https://doi.org/10.1080/10601329808002005

[8] Abu-Abdoun II, Ledwith A. Cationic polymerization photochemically and thermally induced by phenothiazine cation radical salts. European Polymer Journal 1997; 33: 1012, 1671-1677. https://doi.org/10.1016/S0014-3057(97)00044-X

[9] Abu-Abdoun II. Cationic Polymerization Induced by Tris-(pbromophenyl) Amine Cation-Radical Salts. Journal of Research Updates in Polymer Science 2019; 2021(10): 3441. https://doi.org/10.6000/1929-5995.2019.08.04

[10] Compton RG., Laing ME, Ledwith A, Abu-Abdoun II. "Polymer-coated electrodes: cyclic voltammetry and chronoamperometry of non-ideal systems - the anodic oxidation of poly(4-vinyl-triphenylamine) films. J Appl Electrochem 1988; 18: 431-440. https://doi.org/10.1007/BF01093759

[11] Abu-Abdoun I, Aal-e-Ali. Photopolymerization of cyclohexene oxide by Phosphonium and Arsonium salts. European Polymer Journal 1993; 29(11): 1445-1450. https://doi.org/10.1016/0014-3057(93)90056-L

[12] Abu-Abdoun II, Ledwith A. Polymerization of cyclohexene oxide by methyl-4-[bis (4-bromophenyl) amino] benzoate cation radical salts. Journal of Polymer Research 2008; 14(4): 269-276.

https://doi.org/10.1007/s10965-007-9106-x

[13] Kondo S, Ohtsuka T, Ogura K, Tsuda K. Convenient Synthesis and Free-Radical Copolymerization of $p$ Chloromethylstyrene. J Macromol Sci Part A - Chem 1979; A13(6): 767-775.

https://doi.org/10.1080/00222337908056687 
[14] Kameyama A, Suzuki M, Ozaki K, Nishikubo T. New Chemical Modification of Polymers with Pendant Chloromethyl Groups Using 1,8 -Diazabicyclo-[5.4.0]-7undecene. Polymer Journal 1996; 28: 155-158. https://doi.org/10.1295/polymj.28.155
[15] Arshady R, Ledwith A. Suspension polymerisation and its application to the preparation of polymer supports. Reactive Polymers 1983; 1(3): 159-174.

https://doi.org/10.1016/0167-6989(83)90015-6

Received on 18-03-2021

Accepted on 27-05-2021

Published on 08-06-2021

https://doi.org/10.6000/1929-5995.2021.10.7

(C) 2021 Ideisan I. Abu-Abdoun; Licensee Lifescience Global.

This is an open access article licensed under the terms of the Creative Commons Attribution Non-Commercial License (http://creativecommons.org/licenses/by-nc/3.0/) which permits unrestricted, non-commercial use, distribution and reproduction in any medium, provided the work is properly cited. 